\title{
Técnicas de estabelecimento da cultura sobre a produção de sementes de capim-pojuca
}

\author{
Seed production of pojucagrass as influenced by crop establishment techniques
}

\author{
Francisco Humberto Dübbern de Souza ${ }^{\mathrm{I}}$ Ronaldo Pereira de Andrade ${ }^{\mathrm{II}}$ Cláudio Takao Karia ${ }^{\mathrm{II}}$
}

RESUMO

\begin{abstract}
O capim-pojuca (Paspalum atratum cv. 'Pojuca') é uma gramínea tropical perene utilizada como pastagem cultivada. A produção de sementes dessa cultivar no ano agrícola do estabelecimento da cultura é irregular e, por essa razão, entre outubro/2002 e maio/2003, foi realizado um experimento em Planaltina (DF) para avaliar efeitos de épocas de semeadura e de densidade de plântulas no estabelecimento sobre a produtividade de sementes puras. As quantidades de sementes disponíveis à colheita manual foram influenciadas por época de semeadura e por densidade populacional de plântulas. Semeadura tardia (final da primavera) resultou em produtividade reduzida em conseqüência de redução do número de inflorescências $\mathrm{m}^{-2}$. Semeadura realizada em meados da primavera resultou em produtividades reduzidas por tombamento das plantas. Os efeitos adversos de épocas foram atenuados por redução na densidade populacional de plântulas, mas seu impacto sobre a produtividade de sementes foi menor que o resultante de épocas de semeadura. Nesse experimento, a maior produtividade de sementes puras $(331 \mathrm{~kg}$ $\mathrm{ha}^{-1}$ ), no ano agrícola de estabelecimento da cultura resultou de semeadura realizada em meados de novembro $e$ onde, por ocasião do estabelecimento, havia 10 plântulas $\mathrm{m}^{-2}$.
\end{abstract}

Palavras-chave: gramínea tropical, florescimento, perfilhamento, tombamento.

\section{ABSTRACT}

Pojucagrass (Paspalum atratum cv. 'Pojuca') is a perennial tropical grass used as cultivated pasture. Seed production of this cultivar is erratic, especially in the year of the seed crop establishment. Between October 2002 and May 2003, an experiment was carried out in Planaltina (DF),
Brazil, to evaluate the effects of time of sowing and of seedling population densities upon the seed production potential of this grass in the year of the crop establishment. Pure seed yield, harvested by means of the 'sweating' method, was affected both by time of sowing and by seedling densities. As time of sowing was delayed to late Spring, yield was reduced in association with a reduction in inflorescence density. In ealier sowing (mid Spring), seed yield was reduced as a consequence of plant lodging. The adverse effects of delayed sowing upon pure seed yield was attenuated by lower seedling population densities but this effect was not as pronounced as that resulting from time of sowing. Thus, the highest pure seed yield ( $\left.331 \mathrm{~kg} \mathrm{ha}^{-1}\right)$ in the year of crop establishment resulted from a mid-November sowing and where there were 10 seedlings $\mathrm{m}^{-2}$.

Key words: tropical grass, flowering, tillering, lodging.

\section{INTRODUÇÃO}

O capim-pojuca (Paspalum atratum Swallen) é uma gramínea tropical perene, cespitosa, nativa do continente sul-americano. Em 2000, um acesso dessa espécie (BRA-009610) foi liberado para uso como pastagem cultivada no Brasil, sob o nome de cultivar 'Pojuca'. Os principais atributos agronômicos de interesse dessa cultivar são: bom potencial forrageiro, adaptação a solos de baixa fertilidade e sujeitos a encharcamentos temporários e facilidade de propagação por sementes.

\footnotetext{
I Embrapa Pecuária Sudeste, CP 339, 13560-970, São Carlos, SP, Brasil. E-mail: fsouza@cppse.embrapa.br. Autor para correspondência.

IIGerência de Sementes e Mudas, Embrapa Transferência de Tecnologia, Brasília, DF, Brasil.

"IIEmbrapa Cerrados, Planaltina, DF, Brasil
} 
Essa cultivar difere da maioria das demais gramíneas tropicais utilizadas como pastagens ao apresentar requisitos específicos de fotoperíodo e de manejo agronômico para a produção de sementes (HARE et al., 2001b). Na Tailândia, onde recebeu nome de cultivar 'Ubon', PHAIKAEW et al. (2001) obtiveram até $800 \mathrm{~kg} \mathrm{ha}^{-1}$ de sementes puras, viáveis no primeiro ano de cultivo, colhidas manualmente, em áreas estabelecidas por mudas. Entretanto, a produtividade variou amplamente entre regiões e, além disso, só foram obtidas produções de sementes no primeiro ano de cultivo, quando o estabelecimento de campos de produção foi feito por meio de mudas ou de plântulas transplantadas; as produções foram nulas nos locais onde o estabelecimento foi feito via sementes (HARE et al., 2001a).

A identificação de técnicas de plantio que possibilitem produções de sementes no primeiro ano agrícola do estabelecimento da cultura pode contribuir à diminuição dos custos das sementes aos consumidores e, portanto, à sua popularização. Assim, o objetivo do presente trabalho foi avaliar efeitos de épocas de semeadura e de densidade de plântulas no estabelecimento sobre o potencial de produção de sementes de Paspalum atratum cv. Pojuca no ano agrícola da sua implantação.

\section{MATERIAL E MÉTODOS}

O experimento foi iniciado em outubro/ 2002 e concluído em maio/2003, em Planaltina - DF (latitude $15^{\circ} 35^{\prime} 30^{\prime}$ S, longitude $47^{\circ} 42^{\prime} 40^{\prime}$ ' W, altitude: $1007 \mathrm{~m}$ acima do nível do mar), onde a precipitação média anual é de $1.572 \mathrm{~mm}$, a temperatura média do mês mais frio (julho) é $18,9^{\circ} \mathrm{C}$ e o clima é do tipo Aw (KÖEPPEN, 1948). Foram avaliados os efeitos de quatro épocas de semeadura (15/outubro, 15/ novembro, $15 /$ dezembro e $15 /$ janeiro) e de três densidades populacionais de plântulas (10, 20 e 40 plântulas $\mathrm{m}^{-2}$ ) sobre a produção de sementes e os seus componentes e de cada tratamento foram feitas quatro repetições. O início em outubro teve como propósito fazer coincidir o primeiro plantio com reinicio do período chuvoso na região.

O delineamento experimental foi o de parcela subdividida no qual 'época de semeadura' foi considerada a parcela principal e 'densidade de plântulas’, a subparcela. O experimento ocupou área de solo LE bem drenado, corrigido e adubado a lanço com base em resultados de análise de solo. O plantio foi feito em linhas espaçadas entre si por $50 \mathrm{~cm}$; as parcelas experimentais mediram $2 \mathrm{~m}$ x $4 \mathrm{~m}$. O número de plântulas/metro linear foi obtido por meio de desbaste manual nas linhas, realizado 21 dias após a semeadura; 30 dias após cada semeadura foram aplicados $50 \mathrm{~kg} \mathrm{~N}$ $\mathrm{ha}^{-1}$, na forma de uréia, nas linhas.
Foram avaliados os seguintes parâmetros: produtividade de sementes puras $\left(\mathrm{kg} \mathrm{ha}^{-1}\right)$, peso (g) de 100 sementes, densidade de perfilhos (número total de perfilhos $\mathrm{m}^{-2}$ ), densidade de inflorescências (número de inflorescências $\mathrm{m}^{-2}$ ), número de racemos/ inflorescência, comprimento $(\mathrm{cm})$ de racemos/ inflorescência, número de espiguetas/racemo. As densidades de perfilhos e de inflorescências foram avaliadas em duas amostras de $0,5 \mathrm{~m}$ de linha.

O comprimento e o número de racemos/ inflorescência foram avaliados em duas subamostras de dez inflorescências coletadas por ocasião da colheita de sementes em cada parcela e das quais foram retirados cinco racemos ao acaso para contagem do número de espiguetas. Por ocasião da colheita, foram também avaliados a altura média (m) e o grau de tombamento das plantas, por meio de escala visual de 0 (nenhuma planta tombada na parcela) a 5 (todas as plantas tombadas).

A produção de sementes foi estimada a partir da colheita de $6 \mathrm{~m}^{2}$ de cada parcela. A colheita foi realizada no momento em que se verificou facilidade de remoção de sementes dos racemos, quando esfregados entre as pontas dos dedos. $\mathrm{Na}$ ocasião, as inflorescências foram cortadas, mantidas à sombra por cinco dias dentro de sacos de ráfia e então batidas manualmente para remoção das sementes. As amostras coletadas foram secas à sombra, peneiradas, embaladas em sacos de papel e mantidas sob condições ambientais de laboratório até serem avaliadas.

\section{RESULTADOS E DISCUSSÃO}

Os efeitos de época de semeadura foram maiores sobre a densidade de perfilhos totais que os efeitos de densidade populacional de plântulas no estabelecimento (Figura 1). Plantios realizados em outubro e novembro resultaram em números idênticos de perfilhos $\mathrm{m}^{-2}$, porém inferiores aos observados nos plantios realizados em dezembro $(\mathrm{P}<0,05)$. Por sua vez, as médias das densidades de perfilhos totais foram semelhantes $(\mathrm{P}>0,05)$ entre as três densidades populacionais de plântulas no estabelecimento (Figura 1). Em muitas espécies de gramíneas, as plantas constituem agrupamentos fisiologicamente integrados de perfilhos semi-independentes. Nos relvados, as populações de perfilhos se ajustam para limites estabelecidos pelo genótipo em resposta a estímulos decorrentes de variações climáticas sazonais, de manejo, de grau de competição entre eles e de estádio de desenvolvimento dos perfilhos; a formação de novos perfilhos é diminuída durante a fase alongamento do pendão floral (MOORE et al., 2004). 

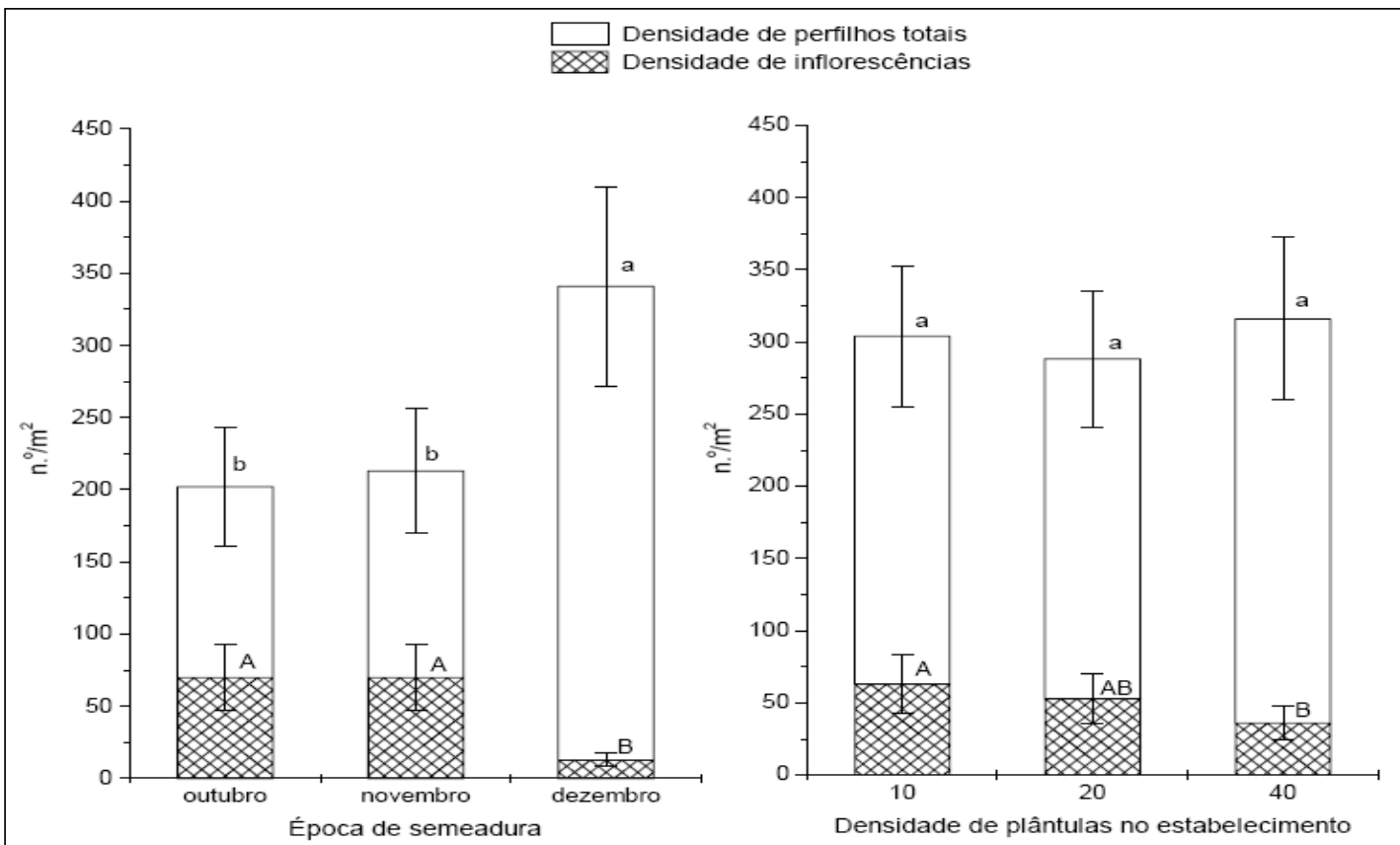

Figura 1 - Efeitos de épocas de semeadura e de densidades populacionais de plântulas no estabelecimento sobre a densidade de perfilhos totais e de inflorescências em capim-pojuca. Planaltina (DF), 2003. Em cada parâmetro, médias seguidas pela mesma letra não diferem entre si pelo teste de Tukey $(\mathrm{P}>0,05)$.

Neste trabalho, época de semeadura teve grande efeito sobre a proporção de perfilhos estimulados ao florescimento (Figura 1), a qual, por sua vez, determinou as densidades de perfilhos totais. As contagens das inflorescências na colheita das sementes foram dificultadas pelo tombamento das plantas e isso pode ter contribuído para a alta observada entre os dados relativos a esse parâmetro, conforme indicam os desvios padrões de cada média (Figura 1). Não se observou tombamento entre as plantas nascidas em dezembro, mas seu impacto foi moderado sobre as plantas nascidas em novembro e severo nas plantas resultantes da semeadura feita em outubro (Tabela 1). No lugar onde havia 10plântulas $\mathrm{m}^{-2}$, o tombamento foi menor que nas demais densidades avaliadas $(\mathrm{P}>0,05)$. Altas precipitações pluviais em um único dia, em fevereiro/2003 (48,5mm) e, em março/2003 (51,4mm), registradas no local pelo Laboratório de Biofísica Ambiental da Embrapa Cerrados, contribuíram para a severidade do problema.

As densidades de inflorescências foram idênticas entre as plantas nascidas em outubro e novembro $(\mathrm{P}>0,05)$, as quais, por sua vez, foram superiores $(\mathrm{P}<0,05)$ à densidade verificada entre as plantas nascidas em dezembro (Figura 1); plantas nascidas em janeiro/2003 não floresceram. A redução

Tabela 1 - Efeitos de épocas de semeadura e de densidades populacionais de plântulas no estabelecimento sobre intensidade de tombamento de plantas de capim-pojuca, avaliada na ocasião da colheita das sementes. Planaltina (DF), 2003.

\begin{tabular}{|c|c|c|c|c|}
\hline \multirow{2}{*}{ Época de Semeadura } & \multicolumn{4}{|c|}{----------Densidade populacional de plântulas no estabelecimento (n⿳00 plântulas $\mathrm{m}^{-2}$ )---------- } \\
\hline & 10 & 20 & 40 & Média \\
\hline & \multicolumn{4}{|c|}{ 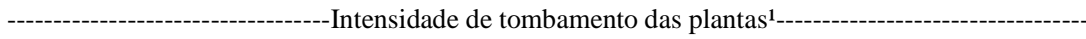 } \\
\hline Outubro & $1,8 \mathrm{Aa}$ & 4,5 Аa & 4,3 Аа & $3,5 \mathrm{a}$ \\
\hline Novembro & $0 \mathrm{Ab}$ & $2,3 \mathrm{Ab}$ & $2,1 \mathrm{Ab}$ & $1,5 \mathrm{~b}$ \\
\hline Dezembro & $0 \mathrm{Ab}$ & 0 Ac & 0 Ac & $0 \mathrm{c}$ \\
\hline Média & $0,6 \mathrm{~B}$ & $2,3 \mathrm{~A}$ & $2,1 \mathrm{~A}$ & \\
\hline CV \% & \multicolumn{4}{|c|}{58,0} \\
\hline
\end{tabular}

1 Avaliado de acordo com estimativa visual ( $0=$ nenhuma planta tombada na parcela; $5=$ todas as plantas tombadas);

Médias seguidas de mesma letra, maiúscula na linha e minúscula na coluna, não diferem entre si $(\mathrm{P}>0,05)$ pelo Teste de Tukey.

Ciência Rural, v.39, n.3, mai-jun, 2009. 
gradual da densidade de inflorescências pode ser atribuída ao aumento do número de perfilhos que não alcançaram o estádio de desenvolvimento mínimo necessário para que fossem induzidos ao florescimento durante o período de ocorrência do fotoperíodo indutivo. As densidades de inflorescências produzidas onde havia 10 e 20 plântulas $\mathrm{m}^{-2}$ por ocasião do estabelecimento foram idênticas $(\mathrm{P}>0,05)$, mas os valores alcançados foram superiores aos observados onde havia 40 plântulas $\mathrm{m}^{-2}$ (Figura 1 ). Esse fato pode ter sido conseqüência do atraso do desenvolvimento dos perfilhos provocado pela maior competição entre eles, a qual por sua vez resultou do aumento da população inicial de plântulas.

Os efeitos dos tratamentos sobre a densidade de inflorescências obedeceram a padrão idêntico ao apresentado pela densidade de perfilhos totais, porém em ordem inversa de grandezas. Assim, os tratamentos que possibilitaram os maiores números de perfilhos totais resultaram nos menores números de inflorescências $\mathrm{m}^{-2}$. Esse efeito foi expresso pela análise e correlação entre esses dados e os dados de densidade de perfilhos totais. O coeficiente de correlação entre todos os dados analisados em conjunto foi $-0,64$ $(\mathrm{P}<0,05)$. Quando cada época de semeadura foi considerada individualmente nessa análise, observouse a existência de correlação $(0,58, \mathrm{P}<0,05)$ entre esses parâmetros no plantio realizado em dezembro, mas não em outubro e novembro; ou seja, nesses casos, a resposta das plantas à indução floral não foi influenciada por densidade populacional de plântulas. No entanto, quando os dados foram analisados, considerando-se cada densidade populacional individualmente, verificou-se que as épocas de semeadura tiveram efeitos marcantes sobre a taxa de fertilidade dos perfilhos, quando as densidades foram de 10 e de 20 plântulas $\mathrm{m}^{-2}$, porém menor no caso de 40 plântulas $\mathrm{m}^{-2}$. Os coeficientes de correlação obtidos, respectivamente para cada uma dessas densidades foram -0,65 ( $\mathrm{P}<0,05),-0,67(\mathrm{P}<0,05)$ e $-0,38(\mathrm{P}>0,05)$.

Dentre os componentes da produção de sementes em gramíneas forrageiras, a densidade de inflorescência é o principal (HOPKINSON \& ENGLISH, 1982), entretanto, em muitas espécies de gramíneas, o número de inflorescências por unidade de área e número de perfilhos totais não se correlacionam positivamente (HUMPHREYS \& RIVEROS, 1986). Reduções do número total de perfilhos durante o período reprodutivo de plantas de várias gramíneas tropicais e subtropicais foram relatadas por MITCHELL et al. (1998) e MOORE et al. (2004). Os dados obtidos nesse trabalho mostram a ocorrência desse fenômeno também no capim-pojuca. A inflorescência exerce forte dominância apical e inibe o crescimento de gemas axilares existentes no perfilho e, conseqüentemente, interrompe a formação de novos perfilhos, até que seu pleno desenvolvimento seja alcançado e desde que as condições de disponibilidade hídrica, de temperatura, de luminosidade e de nutrientes sejam adequadas.

Esse fato deve ser especialmente marcante em gramíneas sensíveis a fotoperíodo como o $\boldsymbol{P}$. atratum cv. 'Pojuca'. Áreas desse capim, se pastejadas ou cortadas a partir de dezembro, produzirão poucas inflorescências e, portanto poucas sementes, mas produzirão mais perfilhos vegetativos (HARE et al., 1999; KALMBACHER et al., 1995), o que poderá contribuir à melhoria da qualidade da forragem consumida pelos animais. No início do período reprodutivo, o corte ou o pastejo das plantas pode resultar na eliminação do meristema apical dos perfilhos induzidos ao florescimento e novos perfilhos desenvolvidos a partir desse evento não terão tempo suficiente para indução fotoperiódica, prejudicando a produção de sementes. Tal comportamento pode ser explicado pelo estímulo ao florescimento proporcionado por fotoperíodo ao $\boldsymbol{P}$. atratum $\mathrm{cv}$. 'Pojuca', que ocorre em resposta quantitativa a dias longos, seguido por resposta qualitativa a dias curtos (HARE et al., 2001b). Neste experimento, o florescimento escasso (dezembro) ou inexistente (janeiro) nas plantas revela que os perfilhos não foram submetidos ao número mínimo de fotoperíodos necessário à indução floral.

Por outro lado, o florescimento profuso entre as plantas de outubro e de novembro (Figura 1), contrariou o verificado por HARE et al. (2001a), em plantas semeadas em maio (equivalente a novembro, no hemisfério sul), em região da Tailândia localizada em latitude muito próxima à de Planaltina (DF), porém, no hemisfério norte. É provável que o florescimento de plantas de capim-pojuca, cultivadas em regiões localizadas em latitudes mais altas, além de mais intenso (HUMPHREYS \& RIVEROS, 1986) seja também antecipado, ocorrendo, portanto em plantas de porte mais baixo.

A época de semeadura, porém não densidade populacional de plântulas, influenciou três das principais características associadas ao número total de espiguetas por inflorescência (Tabela 2). Os números de racemos e de espiguetas/racemo foram semelhantes nas inflorescências das plantas nascidas em outubro e novembro, mas foram superiores $(\mathrm{P}<0,05)$ aos observados nas inflorescências das plantas obtidas do plantio em dezembro. No entanto, os racemos nas plantas nascidas em dezembro foram mais longos $(\mathrm{P}<0,05)$ que aqueles produzidos por plantas nascidas em outubro e em novembro (Tabela 2). Assim, as inflorescências das plantas resultantes da semeadura em dezembro, quando comparadas às resultantes das semeaduras feitas em outubro e novembro, apresentaram racemos mais compridos, porém, menos numerosos e com menor número de espiguetas. 
Tabela 2 - Efeitos de épocas de semeadura sobre características da inflorescência e altura de plantas de capim-pojuca. Planaltina - DF, 2003.

\begin{tabular}{|c|c|c|c|c|}
\hline Época de semeadura & $\begin{array}{l}\text { № de racemos por } \\
\text { inflorescência }\end{array}$ & $\begin{array}{l}\text { Comprimento do racemo } \\
\qquad(\mathrm{cm})\end{array}$ & $\begin{array}{c}\mathrm{N}^{\mathrm{o}} \text { de espiguetas por } \mathrm{cm} \\
\text { de racemo }\end{array}$ & Altura das plantas $(\mathrm{cm})$ \\
\hline Outubro & $15,5 \mathrm{a}$ & $6,0 \mathrm{~b}$ & $12,1 \mathrm{a}$ & $135 \mathrm{a}$ \\
\hline Novembro & 14,5 a & $5,8 \mathrm{~b}$ & 11,8 a & $131 \mathrm{a}$ \\
\hline Dezembro & $9,5 \mathrm{~b}$ & $7,2 \mathrm{a}$ & $8,4 \mathrm{~b}$ & $77 \mathrm{~b}$ \\
\hline $\mathrm{CV} \%$ & 6,7 & 7,1 & 10,8 & 7,6 \\
\hline
\end{tabular}

Médias seguidas de mesma letra na coluna, não diferem entre si (P>0,05) pelo Teste de Tukey.

A altura média das plantas, na ocasião da colheita, foi influenciada pela época de semeadura, mas não pela densidade populacional de plântulas no estabelecimento (Tabela 2). As alturas das plantas nascidas em outubro e novembro foram semelhantes $(\mathrm{P}>0,05)$, entretanto a semeadura de dezembro resultou em plantas de menor altura dentre as épocas testadas $(\mathrm{P}<0,05)$. As diferenças podem ser explicadas pela sensibilidade das plantas ao fotoperíodo. As plantas nascidas em dezembro foram estimuladas a florescer apesar de apresentarem desenvolvimento vegetativo inferior ao das plantas nascidas em outubro e novembro.

Os resultados de análise de correlação entre os dados de altura média das plantas e de índice de tombamento documentam esse fato e permitem concluir que quanto maior a altura das plantas, maior foi o tombamento. O coeficiente de correlação do conjunto de todos os dados foi de $0,56(\mathrm{P}<0,05)$. Esse mesmo teste revelou a inexistência de correlação entre esses conjuntos de dados, quando o efeito época foi considerado individualmente. Isso significa que, em cada época, o índice de tombamento não foi influenciado pela densidade de plântulas no estabelecimento.
Entretanto, ao se considerarem as densidades de semeadura, os coeficientes de correlação foram 0,44 $(\mathrm{P}>0,05), 0,71(\mathrm{P}<0,05)$ e $0,70(\mathrm{P}<0,05)$, respectivamente para as densidades de 10, 20 e 40plântulas $\mathrm{m}^{-2}$, mostrando que o tombamento esteve associado à época de plantio, especialmente, no caso das duas densidades mais altas. Assim, o problema diminuiu, à medida que a densidade de plântulas no estabelecimento foi reduzida e a data da semeadura postergada; ou seja, os efeitos dos tratamentos sobre a altura das plantas as tornaram mais ou menos susceptíveis a chuvas e ventos excessivos.

$\mathrm{O}$ atraso do plantio causou diminuição do tempo entre a emergência das plântulas e a colheita (Tabela 3). Enquanto, para as plantas nascidas em outubro, esse período foi de 183 dias, para as plantas de dezembro, ele foi de 147 dias. Esse fato explica-se pela natureza da resposta ao fotoperíodo apresentada pelo capim-pojuca (HARE et al., 2001b).

A produtividade de sementes puras do capim-pojuca foi influenciada $(\mathrm{P}<0,05)$ tanto pela densidade de plântulas no estabelecimento quanto pela época de semeadura (Tabela 3). A produtividade diminuiu, à medida que a densidade foi aumentada. Dentre as épocas de semeadura, a realizada em meados de novembro possibilitou as maiores produtividades. Os efeitos dos tratamentos, entretanto, foram

Tabela 3 - Efeitos de épocas de semeadura e de densidades populacionais de plântulas no estabelecimento sobre o número de dias entre a emergência das plântulas e a colheita das sementes e a produtividade de sementes puras de capim-pojuca. Planaltina (DF), 2003.

\begin{tabular}{|c|c|c|c|c|c|c|}
\hline \multirow[t]{2}{*}{$\begin{array}{l}\text { Época de } \\
\text { semeadura }\end{array}$} & \multirow[t]{2}{*}{$\begin{array}{l}\text { Data da colheita } \\
\text { de sementes }\end{array}$} & \multirow[t]{2}{*}{$\begin{array}{l}\text { № dias entre emergência das } \\
\text { plântulas e colheita das sementes }\end{array}$} & \multicolumn{4}{|c|}{$\begin{array}{l}\text { Densidade populacional de plântulas no estabelecimento } \\
\qquad\left(\mathrm{n}^{\circ} \text { plântulas } \mathrm{m}^{-2}\right)\end{array}$} \\
\hline & & & 10 & 20 & 40 & Média \\
\hline & & & -----------.- & ---Sementes & $\mathrm{s}\left(\mathrm{kg} \mathrm{ha}^{-1}\right)-$ & --------- \\
\hline Outubro & $16 / 04 / 2004$ & 183 & 68,7 Ab & $30,2 \mathrm{Ab}$ & $16,8 \mathrm{Ab}$ & 38,5 b \\
\hline Novembro & $19 / 04 / 2004$ & 155 & 331,6 Aa & $221,3 \mathrm{Ba}$ & $153,2 \mathrm{Ba}$ & $235,4 \mathrm{a}$ \\
\hline Dezembro & $11 / 05 / 2004$ & 147 & $1,8 \mathrm{Ab}$ & $0,7 \mathrm{Ab}$ & $0,4 \mathrm{Ab}$ & $1,0 \mathrm{~b}$ \\
\hline Média & & & $134,0 \mathrm{~A}$ & $84,0 \mathrm{AB}$ & $56,8 \mathrm{C}$ & \\
\hline $\mathrm{CV} \%$ & & & 56,8 & & & \\
\hline
\end{tabular}

Para cada parâmetro, médias seguidas de mesma letra maiúscula nas linhas e minúscula nas colunas não diferem entre si (P>0,05) pelo teste de Tukey.

Ciência Rural, v.39, n.3, mai-jun, 2009. 
interativos; a produtividade mais alta (331,6kg ha-1) resultou de plantio de 10plântulas $\mathrm{m}^{-2}$ em novembro, enquanto, nos plantios realizados em outubro e dezembro, não foram verificados efeitos de densidade populacional de plântulas no estabelecimento.

A produtividade obtida das plantas resultantes de plantio em dezembro foi insignificante, provavelmente, em conseqüência do número reduzido de inflorescências $\mathrm{m}^{-2}$ e à baixa taxa de fertilidade de perfilhos, que são dois importantes componentes de produtividade de sementes em muitas gramíneas (HUMPHREYS \& RIVEROS, 1986). A densidade de espiguetas por racemo e o número de racemos (Tabela 2) também foram reduzidos com a semeadura em dezembro e devem ter contribuído também à menor produção de sementes obtidas nessa época (Tabela 3). O maior comprimento de racemos $(\mathrm{P}<0,05)$ observado entre as plantas nascidas em dezembro foi insuficiente para elevar a produtividade de sementes em níveis equiparáveis aos obtidos nas outras épocas de semeadura testadas.

Entretanto, nem esses nem os demais componentes avaliados (Tabela 2) neste trabalho (número de racemos/inflorescência, comprimento do racemo e número de espiguetas) explicam as diferenças de produtividades de sementes verificadas entre as plantas nascidas em outubro e novembro $(\mathrm{P}>0,05)$. Nessas plantas, as diferenças observadas revelaramse inversamente correlacionadas ao grau de tombamento. Assim, é provável que, em anos ou regiões quando e onde não ocorrem ventos fortes e/ou chuvas tormentosas, durante o período reprodutivo dessa espécie, a produtividade de sementes puras de plantas obtidas de semeaduras realizadas no início da primavera possam ser equivalentes às obtidas em plantios realizados até os meados da primavera.

De qualquer modo, os dados obtidos indicaram a vantagem de baixas densidades populacionais de plântulas no estabelecimento como forma de atenuar possíveis problemas de tombamento. Foram evidenciados efeitos marcantes dos tratamentos sobre a fração da produtividade de sementes disponíveis à colheita em determinado momento. Por interferir sobre características de desenvolvimento das plantas tais como densidade de inflorescências, porte e, provavelmente, espessura e peso dos perfilhos, de forma isolada ou interativa, épocas de semeadura e densidade de plântulas no estabelecimento alteraram as probabilidades de reduções dessa produtividade, em função de eventos climáticos adversos.

\section{CONCLUSÕES}

A produtividade de sementes puras, colhidas pelo 'método manual da pilha', foram influenciadas por época de semeadura e por densidade populacional de plântulas no estabelecimento. Nos plantios tardios, ou seja, no final da primavera (dezembro), a produtividade de sementes puras foi reduzida em conseqüência da diminuição das inflorescências $\mathrm{m}^{-2}$. Por outro lado, nos plantios realizados em meados da primavera (outubro), as produtividades foram reduzidas por tombamento das plantas, facilitado por crescimento vegetativo exuberante ocorrido até o florescimento. Os efeitos adversos de épocas sobre a produtividade de sementes puras foram atenuados pela diminuição da densidade populacional de plântulas, mas os efeitos desse tratamento foram menores que os resultantes de época de semeadura. Assim, neste experimento, a maior produtividade de sementes puras no ano agrícola de estabelecimento da cultura resultou de semeadura realizada em meados de novembro e, na qual, por ocasião do estabelecimento, havia 10 plântulas $\mathrm{m}^{-2}$.

\section{REFERÊNCIAS}

HARE, M.D. et al. Method and time of establishing Paspalum atratum seed crops in Thailand. Tropical Grasslands, Saint Lucia, v.35, p.19-25, 2001a.

HARE, M.D. et al. Juvenility and long-short day requirement in relation to flowering of Paspalum atratum in Thailand. Tropical Grasslands, Saint Lucia, v.35, p.139-143, 2001b.

HARE, M.D. et al. Method of seed harvest, closing date and height of closing cut affect seed yield and seed yield components in Paspalum atratum in Thailand. Tropical Grasslands, Saint Lucia v.33, p.82-90, 1999.

HOPKINSON, J.M.; ENGLISH, B.H. Spikelet population dynamics in seed crops of Panicum maximum cv. 'Gatton'. Seed Science and Technology, Zurich, v.10, p.379-403, 1982.

HUMPHREYS, L.R.; RIVEROS, F. Tropical pasture seed production. 3.ed. Roma: FAO, 1986. 203p. (FAO Plant Production and Protection Paper, 8).

KALMBACHER, R.S. Effect of rest period length prior to Atra paspalum seed harvest. Proceedings of the Soil and Crop Science Society of Florida, Gainesville, v.54, p.1-5, 1995.

KÖEPPEN, W. Climatología. Mexico: Fondo de Cultura Económica, 1948. 478p.

MITCHELL, R.B. et al. Tiller demographics and leaf area index of four perennial grasses. Agronomy Journal, Madison, v.90, p.47-53, 1998.

MOORE, K.J. et al. Physiology and developmental morphology. In: MOSER, L.E. et al. (Eds.). Warm-season $\left(\mathbf{C}_{4}\right)$ grasses. Madison: American Society of Agronomy, 2004. Cap.6, p.179215 .

PHAIKAEW, C. et al. Maximising seed yield and seed quality of Paspalum atratum through choice of harvest method. Tropical Grasslands, Saint Lucia, v.35, p.11-18, 2001. 